\title{
Índice de reflectancia solar de revestimientos verticales: potencial para la mitigación de la isla de calor urbana
}

\author{
Solar reflectance index of façade coatings: mitigation \\ potential of urban heat islands
}

\section{Noelia Liliana Alchapar \\ Erica Norma Correa María Alicia Cantón}

Noelia Liliana Alchapar Laboratorio de Ambiente Humano y Consejo Nacional de Investigaciond Científicas y Técnicas Avenida Ruiz Leal S/ N, Pque Gral San Mendoza - Mrgentín CP 5500

Tel.: +54 (261) 524-4346 E-mail: nalchapar@mendozaconicet.gob.ar

Erica Norma Correa Laboratorio de Ambiente Humano y Vivienda Consejo Nacional de Investigaciones

Científicas y Técnicas E-mail: ecorrea@mendozaconicet.gob.ar

María Alicia Cantón Laboratorio de Ambiente Humano y Vivienda Consejo Nacional de Investigaciones Científicas y Técnicas E-mail: macanton@mendozaconicet.gob.ar

Recebido em 31/12/11 Aceito em 13/07/12

\section{Resumen}

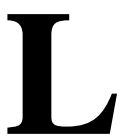

a condición artificial del medio urbano modifica el consumo de energía y el confort térmico. El incremento de las temperaturas de una ciudad en relación a las áreas periféricas conduce a la formación de una Isla de Calor Urbana. Es por ello, que trabajar sobre las propiedades termofísicas de los materiales (techos, pavimentos y fachadas) es una estrategia de mitigación viable para disminuir las temperaturas de una ciudad. El objetivo principal de éste trabajo es estudiar la capacidad de 80 revestimientos para fachadas disponibles regionalmente para mitigar los efectos negativos de la Isla de Calor Urbana, mediante la determinación del Índice de Reflectancia Solar (SRI). El material que posee el comportamiento más eficiente es el Acrílico Rulato Travertino fino marfil (SRI $=100 \%$, Temp. Sup. $\left.=35^{\circ} \mathrm{C}\right)$, mientras el más ineficiente es el Acrílico Llaneado fino gris plomo (SRI = 29\%, Temp. Sup. $=74$ $\left.{ }^{\circ} \mathrm{C}\right)$. No obstante existen alternativas intermedias que resultan del efecto combinado de la composición del material, su color y textura. Esta situación demuestra que es posible mitigar el efecto de isla de calor a partir de una adecuada selección de revestimientos verticales.

Palabras clave: Revestimiento vertical. Índice de reflectancia solar. Isla de calor urbana. Urbanismo bioclimático.

\begin{abstract}
The artificial condition of an urban environment modifies energy consumption and thermal comfort. The higher temperatures in a city center in relation to peripheral areas, lead to the formation of an urban heat island. Therefore, working on the thermo-physical properties of materials (roofs, floors and facades) is a feasible mitigation strategy to reduce the temperature of a city. The main objective of this project is to study the capacity of 80 regionally available façade coatings to mitigate the negative effects of the urban heat island by determining the Solar Reflectance Index (SRI). The material that had the most efficient behavior was Travertine Rulato Acrylic fine ivory (SRI $=100 \%$, Temp. Sup $\left.=35^{\circ} \mathrm{C}\right)$, whereas the most inefficient was the fine dark gray Llaneado Acrylic (SRI $=29 \%$, Temp. Sup $\left.=74^{\circ} \mathrm{C}\right)$. There are also intermediate options that result from the combined effect of the material composition, color and texture. This situation shows that it is possible to mitigate the heat island effect by using the appropriate selection of vertical cladding.
\end{abstract}

Keywords:Facades coating. Solar reflectance index. Urban heat island. Bioclimatic urban design. 


\section{Introducción}

El efecto conocido como isla de calor urbana (ICU) produce mayores temperaturas del aire en el centro de las ciudades comparado con sus áreas suburbanas circundantes. Este fenómeno se relaciona principalmente con la alta densidad edilicia (mayor masa de acumulación), la alta absortancia de los materiales presentes en la ciudad, la escasez de espacios verdes, las características morfológicas de los cañones urbanos, y el calor antropogénico liberado (OKE et al., 1991).

Las altas temperaturas urbanas aumentan los consumos de energía para acondicionamiento térmico de verano, incrementando la demanda eléctrica y los problemas de polución; además sus resultados extienden la huella ecológica, causan disconfort térmico y problemas de salud en sus habitantes. (SANTAMOURIS et al., 2007; SANTAMOURIS; PARAPONIARIS; MIHALAKAKOU, 2007; STATHOPOULOU et al., 2008).

Durante el periodo 2005-2009 en Argentina, la venta de equipos de aire acondicionado creció 100 $\%$ respecto del verano 2005 (INSTITUTO..., 2010). Tendencia que acompaña el aumento en la facturación energética eléctrica residencial. El sector residencial tiende a igualar sus consumos con los principales usuarioseléctricos: el sector industrial (Figura 1).

El incremento en el consumo de energía asociado al endurecimiento de las condiciones climáticas a escala macro - causadas por el cambio climático y a - escala micro - causadas por los efectos de la urbanización, pone de manifiesto la importancia de conocer cuál es el potencial de las propiedades ópticas de la materialidad de la envolvente urbana como herramienta de enfriamiento en el área Metropolitana de Mendoza. Particularmente el Gran Mendoza - Argentina, presenta un efecto de isla de calor cuyas máximas alcanzan los $10^{\circ} \mathrm{C}$, tanto en invierno como en verano, con un valor medio de $6^{\circ} \mathrm{C}$ a lo largo de todo el año. (CORREA; DE ROSA; LESINO, 2007).

Los materiales utilizados en la envolvente edilicia y estructura urbana desempeñan un papel muy importante en el balance térmico de una ciudad. Ellos absorben la radiación solar e infrarroja y disipan parte del calor acumulado a través de procesos de convección y radiación hacia la atmósfera, aumentando la temperatura ambiente (SANTAMOURIS; SYNNEFA; KARLESSIET, 2011). El rendimiento térmico de los materiales está determinado principalmente por sus características ópticas y térmicas. El albedo y emisividad térmica, son los factores más importantes (DOULOS; SANTAMOURIS; LIVADA, 2004).

La incorporación de materiales fríos (con alta reflectividad) en las envolventes edilicias resulta una técnica pasiva eficiente para disminuir la demanda de energía para refrigerar en períodos estivales. Mejorando el microclima de las zonas urbanas mediante la reducción de temperaturas superficiales y la del aire ambiente (SANTAMOURIS; SYNNEFA; KARLESSIET, 2011).
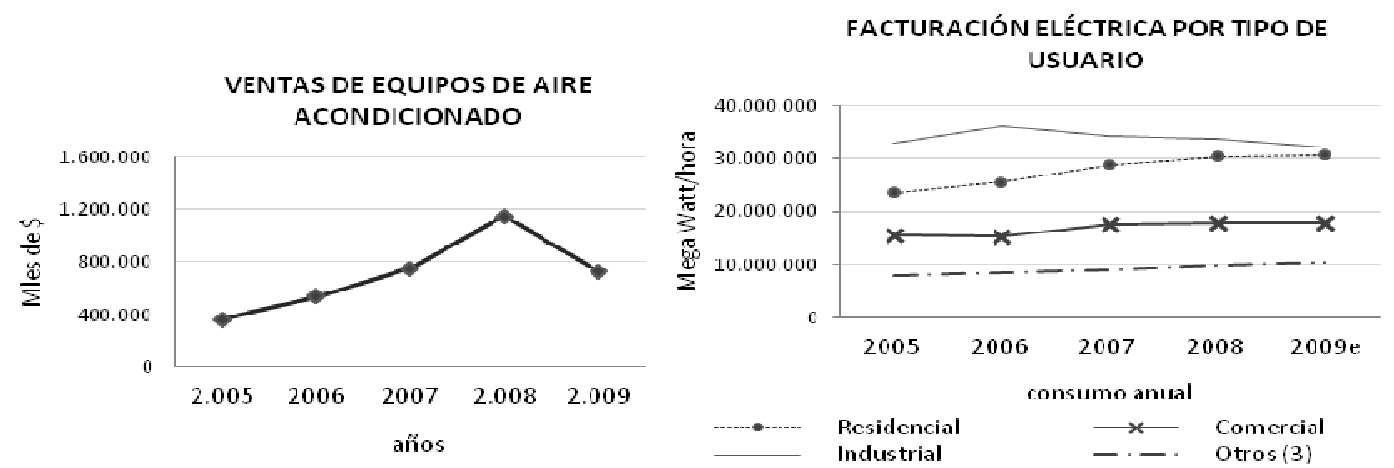

Figura 1 - Venta de equipos de aire acondicionado y facturación energética por tipo de usuario a nivel nacional, durante el período 2005-2009

Fuente: Ministerio de Planificación Federal, Inversión Pública y Servicios. Secretaría de Energía (2011).

\footnotetext{
${ }^{1}$ Otros, incluye los siguientes usuarios: obras sanitarias, alumbrado público, tracción eléctrica, riego agrícola, oficial, consumo de distribuidores y electrificación rural.
} 
Los materiales fríos se caracterizan por:

(a) alta reflectancia solar (â): la reflectancia solar o albedo, mide la capacidad de un material de reflejar la radiación solar incidente, considerando la reflectancia hemisférica de la radiación integrada en el espectro solar; incluyendo reflexión especular y difusa. Es medida en una escala de 0 a 1 (o $0-100 \%)$; y

(b) alta emisión infrarroja ( $\varepsilon$ ): la emitancia infrarroja mide la capacidad de una superficie para liberar -a través de radiación infrarroja - el calor absorbido por el material, en relación con un cuerpo negro de igual temperatura.

Si un material frío se aplica en una envolvente edilicia, esto se traduce en una disminución de las cargas de calor que penetran hacia el interior del edificio y al entorno urbano. Por lo tanto, éstos materiales contribuyen con la reducción de la temperatura ambiente, ya que la intensidad convectiva de calor desde una superficie más fría es más baja. En el gráfico se indican los principios básicos de comportamiento térmico de un material frío (Figura 2).

El objetivo principal de éste trabajo es estudiar la habilidad para mitigar los efectos negativos de la Isla de Calor Urbana de revestimientos verticales texturados disponibles regionalmente, categorizándolos de acuerdo al valor de su Índice de Reflectancia Solar (SRI).

La categorización de materiales de acuerdo a su Índice de Reflectancia Solar (SRI) permite seleccionar los revestimientos adecuados para disminuir las temperaturas superficiales del medio urbano y reducir en consecuencia el consumo energético a escala edilicia. Esta categorización permitirá recomendar aquellos materiales que se encuentran disponibles localmente y que presentan mejor desempeño térmico con el fin de alcanzar en el corto plazo la consecución de ciudades más sostenibles.

Se calcula el Índice de Reflectancia Solar (SRI) de los materiales seleccionados basado en la medida de su reflectividad solar, su emisividad térmica y su temperatura superficial. De este modo, además, es posible comparar internacionalmente los resultados del funcionamiento de los materiales utilizados a nivel local y regional, y al mismo tiempo generar conocimiento en torno a la estandarización de los materiales regionales sentando las bases para propiciar una futura certificación energética tanto a nivel urbano como edilicio.

\section{Metodología \\ Selección y clasificación de materiales}

Con la colaboración de un socio industrial (WeberSanit Gobain) se confeccionaron 80 muestras de $30 \times 30 \mathrm{~cm}$, formadas por tres capas:
(a) soporte;
(b) aditivo; $y$
(c) mortero texturable.

La primera superficie, es una plancha de poliestireno expandido de alta densidad, de $10 \mathrm{~cm}$ de espesor, que no sólo cumple la función de soporte, sino que esta superficie funciona como el límite adiabático respecto de la conductividad del material hacia la tierra. En segundo lugar, se extiende un mortero de $3 \mathrm{~mm}$ de espesor que permite una mejor adherencia del revestimiento a la superficie de poliestireno, y por último, una capa del revestimiento texturado y coloreado.

En éste estudio se analizarán en particular revestimientos verticales de composición acrílica (SIP) y cementicia (CW), difundidos en el mercado regional.

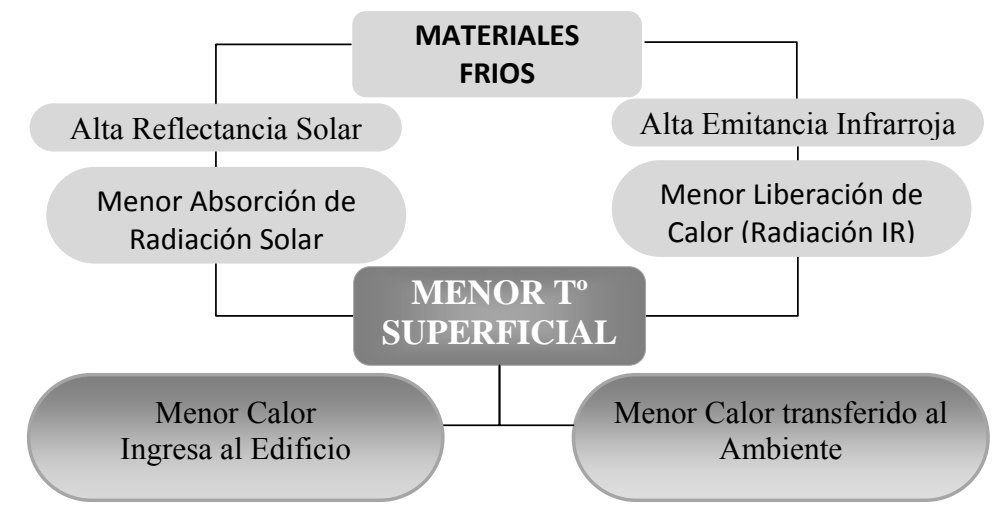

Figura 2 -Principios básicos de materiales fríos

Fuente: Santamouris, Synnefa y Karlessiet (2011). 
Los revestimientos texturados acrílicos (SIP), están compuestos a base polímeros acrílicos, cargas minerales de granulometría múltiple, pigmentos inorgánicos con elevada resistencia $\mathrm{U}$. V., y aditivos químicos.

Los morteros cementicios (CW), están compuestos a base de cemento blanco, marmolinas, cal, pigmentos, aditivos orgánicos e inorgánicos, cargas minerales de granulometría clasificada, resinas sintéticas, funguicidas $\mathrm{y}$ alguicidas en polvo aptos para revestimientos de muros $y$ fachadas.

Para ésta etapa se seleccionaron 8 colores, de acuerdo a la demanda en el mercado local y frecuencia de uso:
(a) blanco;
(b) marfil;
(c) piedra parís;
(d) ocre;
(e) terracota;
(f) gris perla;
(g) gris cemento; y
(h) gris plomo.

Los mismos se describen según el sistema CIE (Comisión Internacional de la Iluminación) según diagrama de color CIELAB (COMISIÓN..., 1937).

Se monitorearon cinco texturas, de granulometría y acabado variado, para la composición acrílica y cementicia. En la composición acrílica, según denominación dada por el fabricante se clasificaron en: rulatotravertino fino (rf) y grueso (rg), llaneado fino (lf) y grueso (lg), granitex mediano (gm). En los revestimientos cementicios $(\mathrm{CW})$ : texturablerulato ( $\mathrm{tr}) \mathrm{y}$ travertino (tt), salpicratesalpic (ss) y planchado (sp), granitex mediano (gm) (Tabla 1).

Tabla 1 - Clasificación de muestras, según composición, textura, terminación ${ }^{2}$

\begin{tabular}{|c|c|c|c|c|c|}
\hline \multicolumn{6}{|c|}{ REVESTIMIENTOS VERTICALES } \\
\hline COMPOSICIÓN & \multicolumn{2}{|c|}{ TEXTURA } & TERMINACIÓN & COLOR & \multirow{4}{*}{$\begin{array}{l}\text { L*a*b } \\
98.618 / 0.005 /-0.010 \\
94.320 /-1.381 / 22.189 \\
67.857 / 6.516 / 23.710\end{array}$} \\
\hline \multirow{8}{*}{$\begin{array}{l}\text { ACRÍLICA } \\
\text { (SIP) }\end{array}$} & \multirow{6}{*}{ 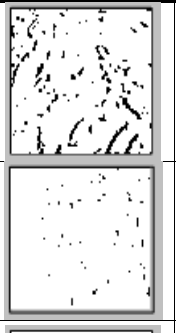 } & \multirow{3}{*}{ Rulato Travertino } & \multirow[t]{3}{*}{ Fino (rf) } & \multirow{3}{*}{$\begin{array}{l}\text { Blanco } \\
\text { Marfil } \\
\text { Piedra Paris }\end{array}$} & \\
\hline & & & & & \\
\hline & & & & & \\
\hline & & \multirow{3}{*}{ Llaneado } & \multirow{3}{*}{$\begin{array}{l}\text { Fino (lf) } \\
\text { Grueso (lg) }\end{array}$} & Ocre & $58.607 / 13.716 / 58.966$ \\
\hline & & & & Terracota & $32.882 / 42.305 / 25.852$ \\
\hline & & & & Gris Perla & $76.309 /-1.156 /-2.14$ \\
\hline & & \multirow{2}{*}{ Granitex } & \multirow{2}{*}{ Medio (gm) } & Verde Hormigón & $58.426 /-5.622 / 7.638$ \\
\hline & & & & Gris Plomo & $50.070 / 2.358 /-2.886$ \\
\hline \multirow{9}{*}{$\begin{array}{c}\text { CEMENTICIA } \\
\text { (CW) }\end{array}$} & & \multirow{3}{*}{ Texturable } & \multirow[b]{3}{*}{ Travertino $(\mathrm{tt})$} & Blanco & $98.618 / 0.005 /-0.010$ \\
\hline & & & & Marfil & $94.320 /-1.381 / 22.189$ \\
\hline & & & & Piedra Paris & $67.857 / 6.516 / 23.710$ \\
\hline & & \multirow{3}{*}{ Salpicrate } & \multirow[t]{2}{*}{ Salpic (ss) } & Ocre & $58.607 / 13.716 / 58.966$ \\
\hline & & & & Terracota & $32.882 / 42.305 / 25.852$ \\
\hline & 4 & & Planchado (sp) & Gris Perla & $76.309 /-1.156 /-2.14$ \\
\hline & & \multirow{3}{*}{ Granitex } & \multirow{3}{*}{ Medio (gm) } & Verde Hormigón & $58.426 /-5.622 / 7.638$ \\
\hline & & & & & \\
\hline & & & & Gris Plomo & $50.070 / 2.358 /-2.886$ \\
\hline
\end{tabular}

Nota: color de acuerdo a CIELab.

\footnotetext{
${ }^{2}$ Designación dada por el fabricante "Weber-SanitGobain". Argentina S.A.
} 


\section{Registro térmico y óptico de muestras}

El monitoreo se realizó durante el mes de febrero y marzo del año 2011. De la serie de mediciones los datos que se reportan en este estudio corresponden al 10 de marzo, por ser un día típico de verano mendocino.

Con registros de radiación solar (I) igual a 883.74 $\mathrm{W} / \mathrm{m} 2$, temperatura media de aire (Ta) de $33{ }^{\circ} \mathrm{C}$, humedad relativa de $36.4 \%$ y velocidades viento promedio (v) de $1.2 \mathrm{~m} / \mathrm{s}$.

Para el calcular el SRI de acuerdo a lo establecido por la norma ASTM E1980 (AMERICAN..., 2011a), se midieron las siguientes variables: emisividad $(\varepsilon)$, albedo (â), coeficiente convección (hc) y temperatura superficial (Ts), correspondiente a las $13.00 \mathrm{hs}$.

Tanto el albedo como la emisividad, son propiedades que afectan directamente la temperatura superficial de un material (BRETZ; AKBARI, 1997; SIEGEL; HOWELL, 2002), ya que determinan la fracción de energía solar que incide y que se libera.

Para el cálculo de emisividad $(\varepsilon)$ se empleó un sensor de temperatura de termocupla tipo $\mathrm{T}$ asociado a un data logger hobbo U12, el mismo fue programado en registros de medición de temperatura superficial en intervalos de 2 segundos. El valor del flujo radiante emitido por el material es comparado con el dato que registra un termómetro IR Fluke 568 con ajuste de emisividad. De modo tal que la emisividad del material corresponde a aquella que hace coincidir la temperatura de la termocupla con la del termómetro IR (AMERICAN..., 2006).

Para determinar el valor del albedo (â), se utilizó un albedómetro tipo Kipp \& Zonen CMA11. Éste instrumento posee un rango espectral de 285 a $2800 \mathrm{~nm}$, con una irradiancia solar máxima de $4000 \mathrm{~W} / \mathrm{m}^{2}$ (KIPP \& ZONEN, 2012). El albedómetro registra la radiación solar recibida sobre superficie horizontal y la radiación solar reflejada, de éste modo se determina por diferencia, el albedo de cada revestimiento.
El coeficiente global de convección (hc) se incrementa con la velocidad de viento de acuerdo a la Ecuación 1 (DUFFIE; BECKMAN, 1991):

$\mathrm{h}_{\mathrm{c}}=2.8+3 \mathrm{v}$ Ec. 1

Para velocidad de viento $<5 \mathrm{~m} / \mathrm{s}$

Donde:

$\mathrm{v}=$ velocidad de viento. $\mathrm{m} / \mathrm{seg} .(1.2 \mathrm{~m} / \mathrm{s})$.

La conductividad térmica de cada material se ha despreciado, ya que sus espesores son semejantes y además se trabaja con límite adiabático respecto de la conductividad a tierra (superficie de poliestireno expandido)

Los registros del comportamiento térmico superficial (Ts) se tomaron con la cámara IR Fluke Ti 55 que detecta la radiación infrarroja de onda larga en el rango de 7.5 a 14 micras dentro del espectro electromagnético. Con este instrumento se obtuvieron imágenes térmicas que registran el calor radiante de cada material. En las fotografías termográficas cada píxel contiene un valor de temperatura determinado. El software Smart-View 2.1, a través de algoritmos, asigna un color específico que corresponde a un valor de temperatura en las coordenada x-y de la imagen.

La energía radiante registrada por la cámara infrarroja no sólo está en función de la temperatura del objeto, sino que también de su emisividad. La misma fue seteada previamente de acuerdo al valor medido para cada material in situ (Figura 3).

De acuerdo a la norma ASTM D2244 (AMERICAN..., 2011b), para determinar la composición de color de las muestras se utilizó un luminancímetro colorímetro Konica Chroma Meter CS-100A. Éste instrumento percibe las longitudes de onda de luz reflejada como valor numérico según diagrama de cromaticidad Yxy. Mediante el software Data Management CS- C10W se expresa en CIELAB los datos obtenidos en cada muestra. Donde el valor de $\mathrm{L}^{*}$ define la claridad, la $\mathrm{a}^{*}$ denota el valor rojo/verde y la $b^{*}$ el valor amarillo/azul.

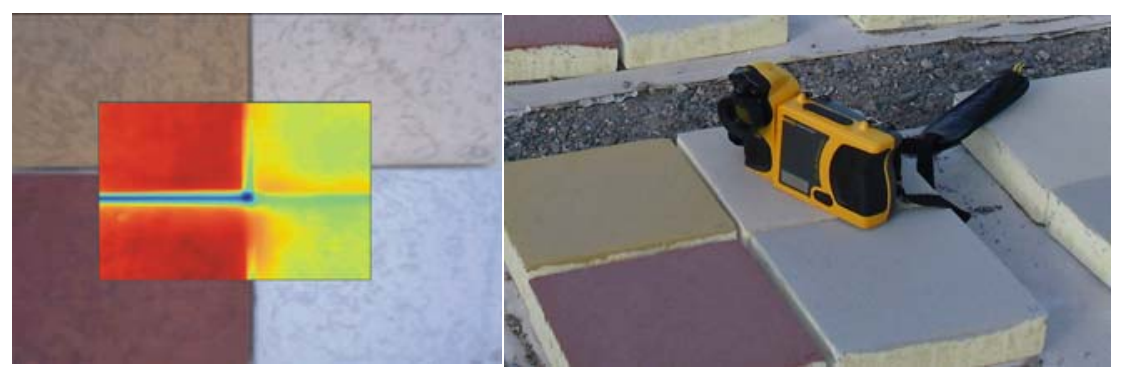

Figura 3 - Evaluación térmica y óptica de los materiales en el predio 


\section{Índice de Reflectividad Solar (SRI)}

El Índice de Reflectividad Solar se obtiene bajo la norma ASTM E1980 (AMERICAN..., 2011a). Éste es un indicador que incorpora la reflectancia y la emitancia en un único término que representa la temperatura de una superficial horizontal, o de baja pendiente $\left(<9.5^{\circ}\right)$, de una material opaco expuesto al sol. Permitiendo una comparación directa entre superficies con diferentes propiedades ópticas (albedo y emisividad). Se calcula utilizando ecuaciones basadas en datos previamente definidos y medidos de reflectancia y emitancia solar, y se expresa como un valor $(0,0$ a 1,0$)$ o como porcentaje $(0 \%$ a $100 \%)$.

El SRI cuantifica el calor que acumularía un material en relación a una superficie patrón blanca y una negra, bajo condiciones ambientales estándar. Se define como patrón negro a un material con una reflectancia de 0.05 y una emitancia 0.90 , cuyo valor es igual a 0 ; y el patrón blanco equivale a 1 (o 100\%), con una reflectancia 0.80 y una emitancia 0,90 .

Este método se utiliza para superficies con emisividades mayores a 0.01 y temperaturas superficiales menores a $150{ }^{\circ} \mathrm{C}$.

Para una superficie expuesta al sol y aislada por debajo, la temperatura superficial de equilibrio (Ts) se obtiene a partir de norma ASTM E1980 (AMERICAN... 2011a) (Ec. 2):

$T s=309.07+\frac{(1066.07 \alpha-31.98 \varepsilon)}{\left(6.78 \varepsilon+h_{c}\right)}-\frac{\left(890.94 \alpha^{2}+2153.8 \alpha \varepsilon\right)}{\left(6.78 \varepsilon+h_{c}\right)^{2}}$

Ec. 2
Dónde:

$\alpha=$ absortancia solar $=1$ - reflectancia solar;

$\varepsilon=$ emisividad térmica; $\mathrm{y}$

hc $=$ coeficiente global de convección. W.m-2.K-1.

El valor adoptado para he es de 6,4 W.m-2.K-1, valor que deriva del cálculode la ecuación 1.

El índice de Reflectividad Solar se define como (Ec. 3):

$S R I=100 \frac{T_{b}-T s}{T_{b}-T_{w}}$

Dónde:

$\mathrm{Ts}=$ temp. superficial en estado estacionario. K;

$\mathrm{Tb}=$ temperatura superficial patrón negro. $\mathrm{K} ; \mathrm{y}$

$\mathrm{Tw}=$ temperatura superficial patrón blanco. $\mathrm{K}$.

\section{Obtención de temperaturas} superficiales de patrones y muestras.

Mediante el uso de la Ecuación 2 se calcularon las temperaturas superficiales de los patrones, bajo condiciones ambientales locales (Tabla 2).

A través del cálculo de la Ecuación 3 se obtuvieron los índices de reflectividad solar (SRI) para los revestimientos acrílicos y cementicios (Tabla 3).

Tabla 2 - Índice de Reflectividad Solar de superficies patrones

\begin{tabular}{l|c|c|c|c}
\hline \multicolumn{1}{c|}{ PATRONES } & â & $\boldsymbol{\varepsilon}$ & Ts $\left({ }^{\mathbf{0}} \mathbf{C}\right)$ & SRI (\%) \\
\hline NEGRO $(\mathrm{Tb})$ & 0.05 & 0.90 & 88 & 0 \\
\hline BLANCO $(\mathrm{Tw})$ & 0.80 & 0.90 & 37 & 100 \\
\hline
\end{tabular}


Tabla 3 - Enumeración de los revestimientos verticales estudiados con sus respectivos códigos asignados, denominaciones, temperaturas superficiales (Ts) en grados Celsius, albedo (â), emisividad $(\varepsilon)$, y Índice de Reflectancia Solar (SRI) en porcentajes

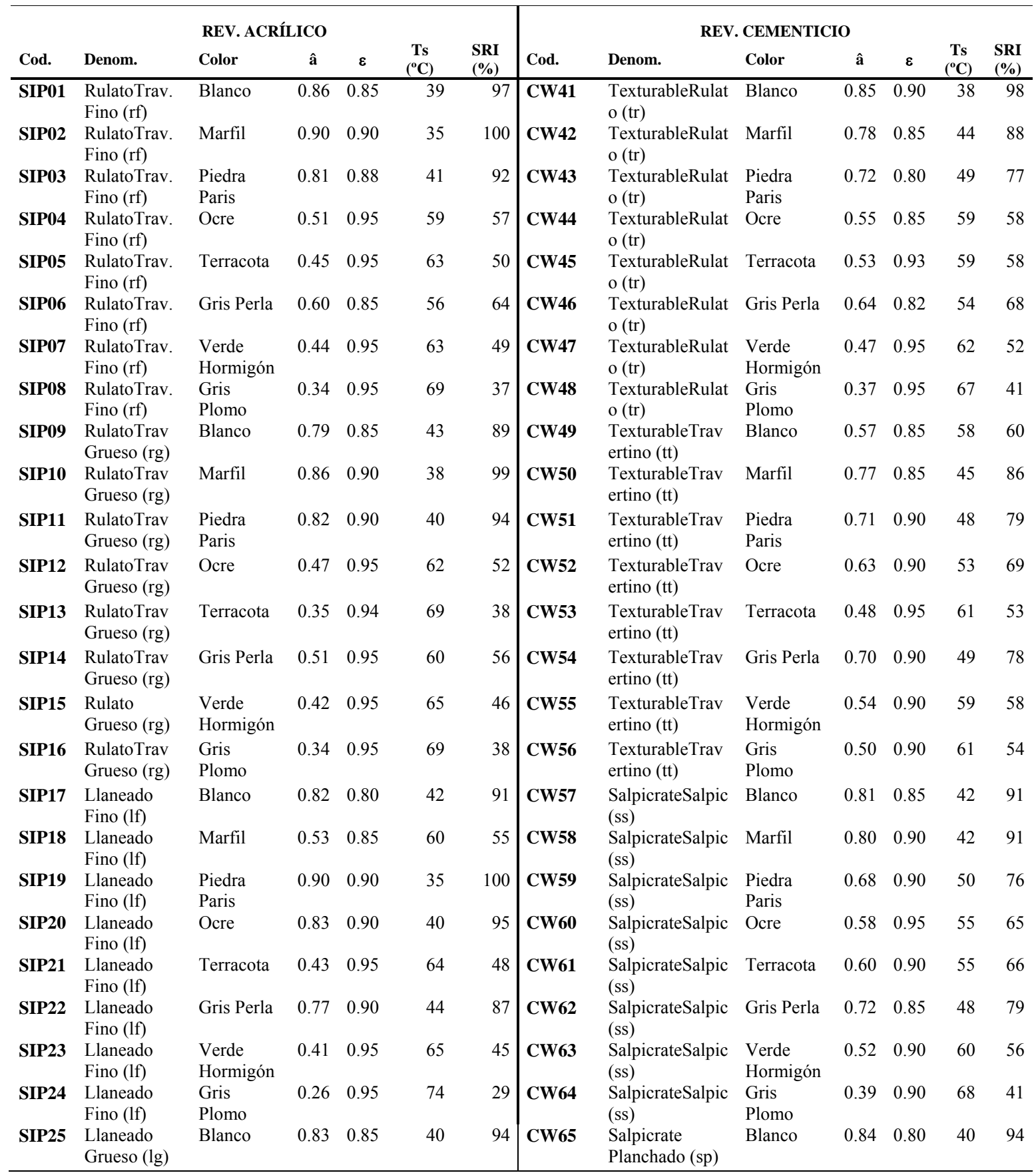


Tabla 3 - Enumeración de los revestimientos verticales estudiados con sus respectivos códigos asignados, denominaciones, temperaturas superficiales (Ts) en grados Celsius, albedo (â), emisividad $(\varepsilon)$, y Índice de Reflectancia Solar (SRI) en porcentajes (continuación)

\begin{tabular}{|c|c|c|c|c|c|c|c|c|c|c|c|c|c|}
\hline SIP26 & $\begin{array}{l}\text { Denom. } \\
\text { Llaneado } \\
\text { Grueso (lg) }\end{array}$ & Marfil & 0.75 & 0.85 & 46 & 83 & CW66 & $\begin{array}{l}\text { Salpicrate } \\
\text { Planchado (sp) }\end{array}$ & Marfil & 0.75 & 0.85 & 46 & 83 \\
\hline SIP27 & $\begin{array}{l}\text { Llaneado } \\
\text { Grueso (lg) }\end{array}$ & $\begin{array}{l}\text { Piedra } \\
\text { Paris }\end{array}$ & 0.58 & 0.85 & 57 & 62 & CW67 & $\begin{array}{l}\text { Salpicrate } \\
\text { Planchado (sp) }\end{array}$ & $\begin{array}{l}\text { Piedra } \\
\text { Paris }\end{array}$ & 0.63 & 0.85 & 54 & 68 \\
\hline SIP29 & $\begin{array}{l}\text { Llaneado } \\
\text { Grueso (lg) }\end{array}$ & Terracota & 0.50 & 0.95 & 60 & 56 & CW69 & $\begin{array}{l}\text { Salpicrate } \\
\text { Planchado (sp) }\end{array}$ & Terracota & 0.48 & 0.95 & 61 & 54 \\
\hline SIP30 & $\begin{array}{l}\text { Llaneado } \\
\text { Grueso (lg) }\end{array}$ & Gris Perla & 0.74 & 0.90 & 46 & 83 & CW70 & $\begin{array}{l}\text { Salpicrate } \\
\text { Planchado (sp) }\end{array}$ & Gris Perla & 0.67 & 0.85 & 51 & 73 \\
\hline SIP33 & $\begin{array}{l}\text { Granitex } \\
\text { Medio (gm) }\end{array}$ & Blanco & 0.86 & 0.85 & 39 & 98 & CW73 & $\begin{array}{l}\text { Granitex } \\
\text { Medio (gm) }\end{array}$ & Blanco & 0.82 & 0.85 & 41 & 92 \\
\hline SIP34 & $\begin{array}{l}\text { Granitex } \\
\text { Medio (gm) }\end{array}$ & Marfil & 0.77 & 0.85 & 45 & 86 & CW74 & $\begin{array}{l}\text { Granitex } \\
\text { Medio (gm) }\end{array}$ & Marfil & 0.77 & 0.85 & 45 & 85 \\
\hline SIP35 & $\begin{array}{l}\text { Granitex } \\
\text { Medio (gm) }\end{array}$ & $\begin{array}{l}\text { Piedra } \\
\text { Paris }\end{array}$ & 0.67 & 0.85 & 51 & 73 & CW75 & $\begin{array}{l}\text { Granitex } \\
\text { Medio (gm) }\end{array}$ & $\begin{array}{l}\text { Piedra } \\
\text { Paris }\end{array}$ & 0.73 & 0.90 & 47 & 82 \\
\hline SIP36 & $\begin{array}{l}\text { Granitex } \\
\text { Medio (gm) }\end{array}$ & Ocre & 0.72 & 0.90 & 47 & 81 & CW76 & $\begin{array}{l}\text { Granitex } \\
\text { Medio (gm) }\end{array}$ & Ocre & 0.53 & 0.90 & 59 & 57 \\
\hline SIP37 & $\begin{array}{l}\text { Granitex } \\
\text { Medio (gm) }\end{array}$ & Terracota & 0.44 & 0.95 & 63 & 49 & CW77 & $\begin{array}{l}\text { Granitex } \\
\text { Medio (gm) }\end{array}$ & Terracota & 0.53 & 0.90 & 59 & 57 \\
\hline
\end{tabular}

Las Figuras 4 y 5 describen el nivel de SRI de cada revestimiento para la composición acrílica y cementicia respectivamente.

\section{Resultados}

Los resultados serán expresados de acuerdo al criterio de clasificación que se expresa en la Tabla 1.

En la primera parte se analiza de forma general el comportamiento óptico (albedo) y el Índice de Reflectancia Solar (SRI) de todos los revestimientos analizados, de acuerdo a su composición, textura, terminación color.
En la segunda parte, con el propósito de profundizar los resultados derivados de la investigación, se analizan por separado los revestimientos de acuerdo a su composición. Dentro de éstos dos grandes grupos (acrílicos y cementicios) se comparan los efectos de la modificación de una de las variables de clasificación - terminación, textura o color -, manteniendo constante las restantes. Por ejemplo se compara el comportamiento térmico de un revestimiento acrílico de igual terminación y textura pero diferente color, y así sucesivamente con las combinatorias posibles de variables intervinientes. 

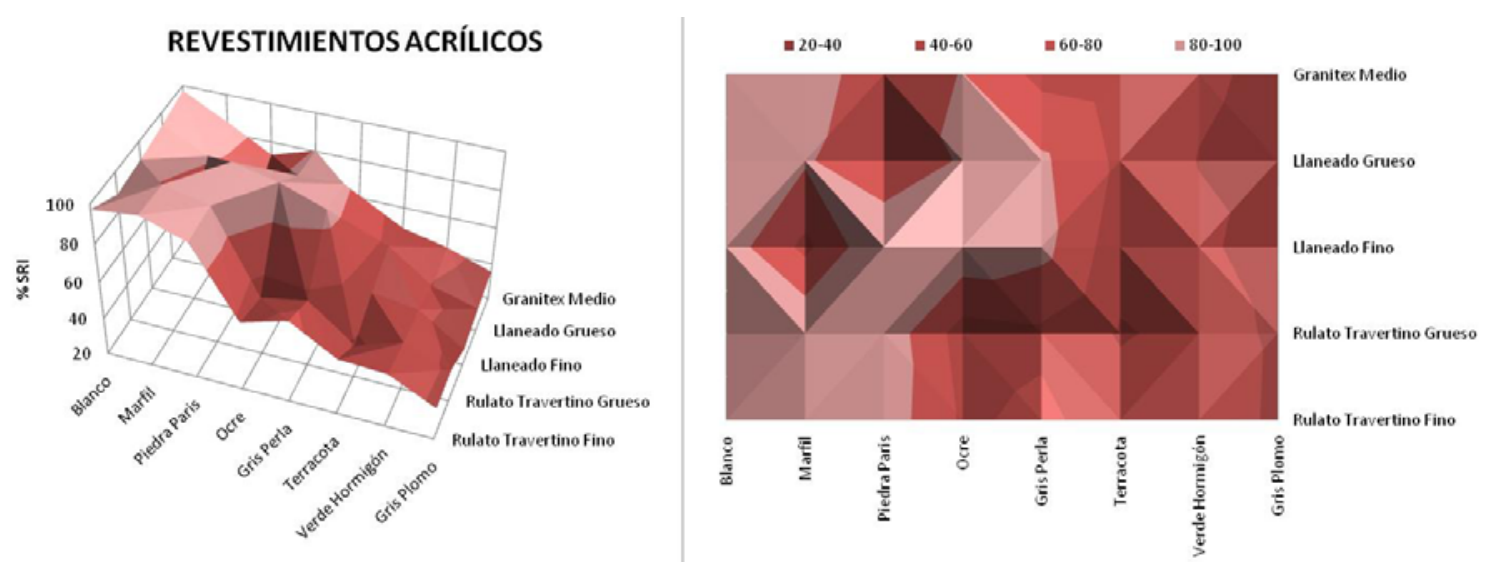

Figura 4 -Índice de Reflectancia Solar de revestimientos acrílicos (SIP), según color, textura y terminación
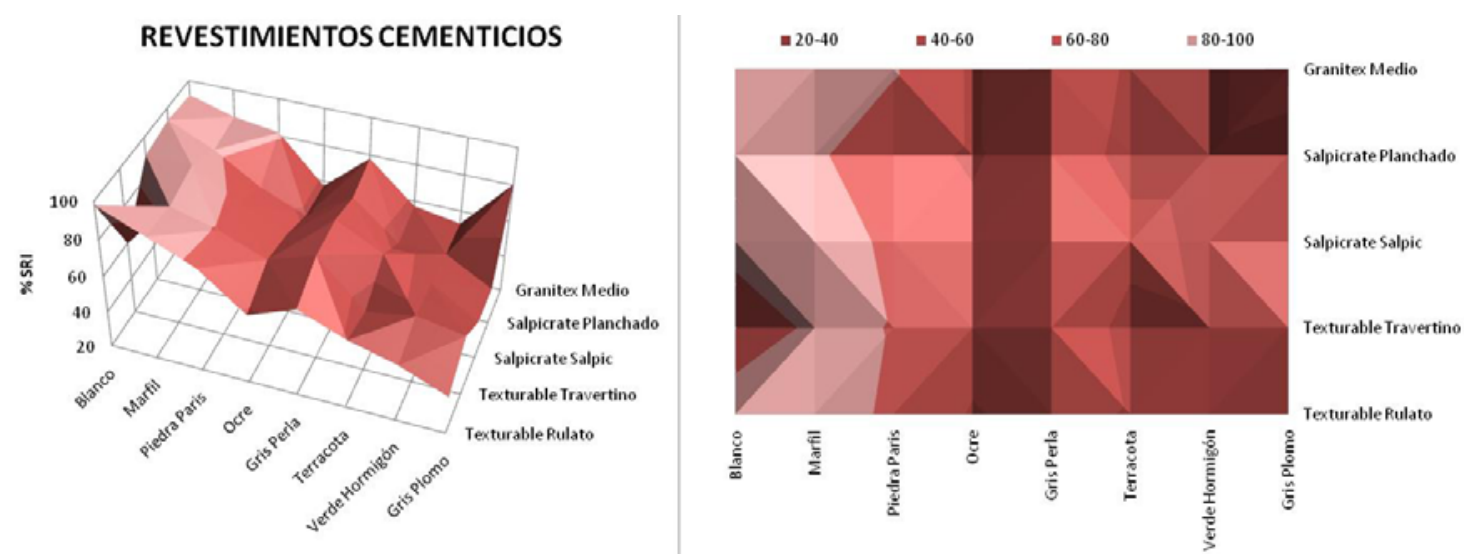

Figura 5 -Índice de Reflectancia Solar de revestimientos cementicios (CW), según color, textura y terminación

\section{Primera etapa de análisis \\ Máximos niveles de albedo}

Los niveles de albedo (â) en el total de las muestras oscilan entre 0.90 y 0.29 . Los materiales que poseen mayor reflectancia solar son los acrílicos RulatoTravertino fino blanco -SIP02- y el Llaneado fino piedra parís-SIP19-, en donde â es igual a 0.90 . Los altos valores de albedo de ambos materiales, corresponden con las menores temperaturas registradas en el total de las muestras.

Debido a la falta de uniformidad de las temperaturas superficiales (Ts) de un mismo material estudiado, los valores corresponden al promedio del total de la superficie horizontal. Ésta escasa uniformidad se debe principalmentea una concentración de pigmentación en algunos sectores, rugosidades diversas de una misma textura, o por componentes varios del mortero. Éste efecto se acentúa en terminaciones de granulometría gruesa (Figura 6).

\section{Cálculo de SRI de revestimientos de composición acrílica (SIP) y cementicia (CW)}

El $43 \%$ de los materiales acrílicos posee entre el $100-80 \%$ de habilidad para mitigar los efectos negativos de ICU y tan solo $28 \%$ de los cementicios integran éste rango. Dentro de los porcentajes intermedios, se observa que en ambas composiciones la mayor frecuencia está situado en el rango de $60-40 \%$ de SRI. Se encuentran dentro de este rango el $35 \%$ de los revestimientos de acrílico y el $40 \%$ de los revestimientos cementicios evaluados. Mientras que el $15 \%$ de los acrílicos y el $3 \%$ de los cementicios, poseen índices de reflectividad inferiores al $40 \%$ (Figura 7 ). 
SIP 02
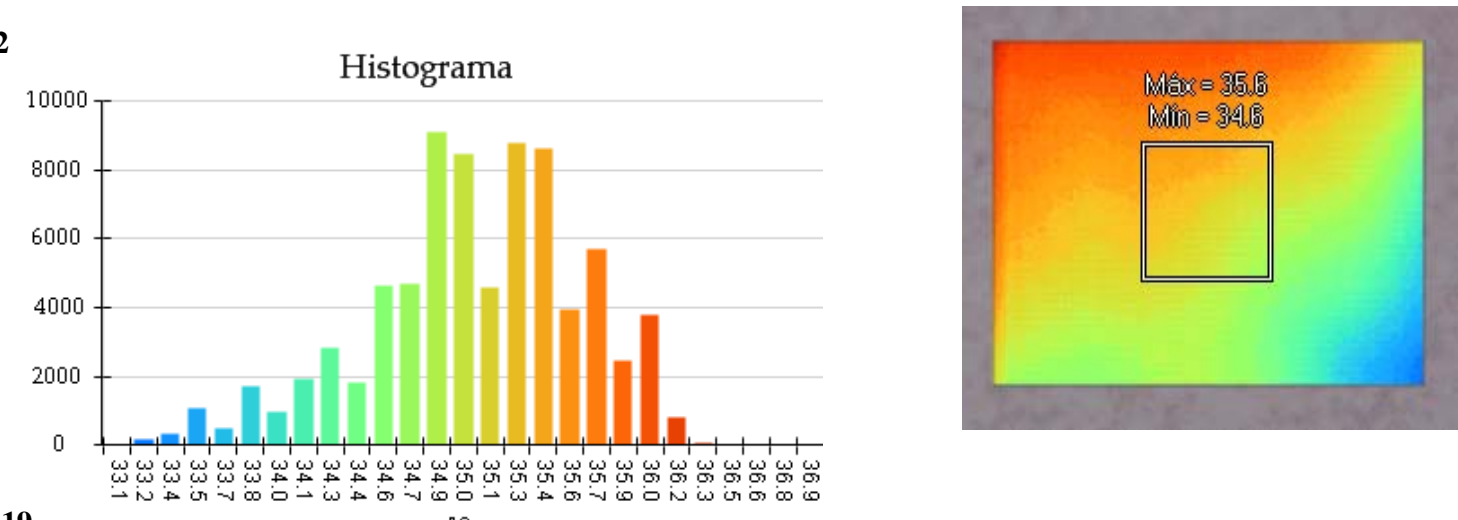

SIP 19

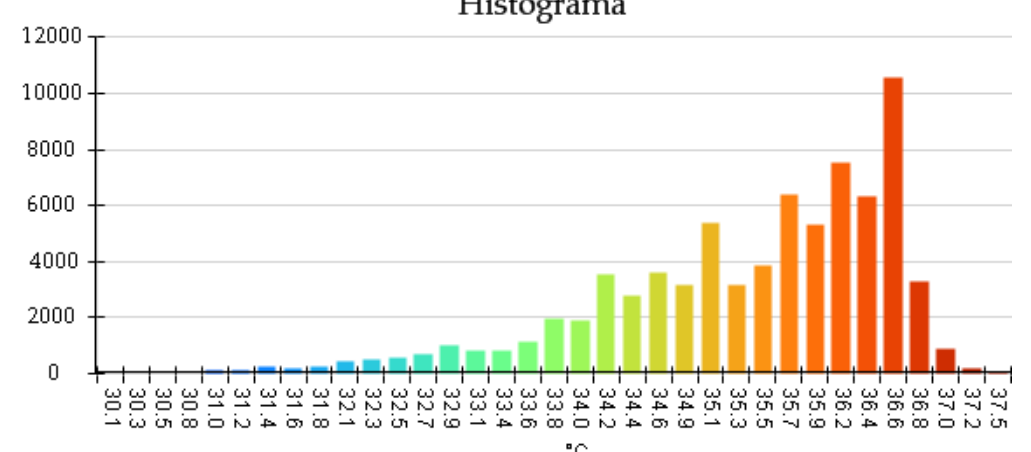

Histograma

Figura 6 - Distribución térmica registrada con cámara IR de revestimientos SIP 02 y SIP 19

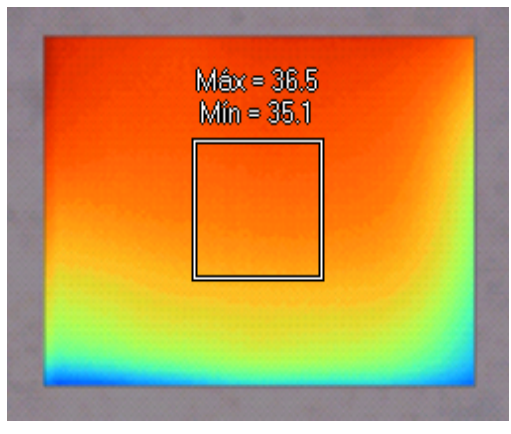

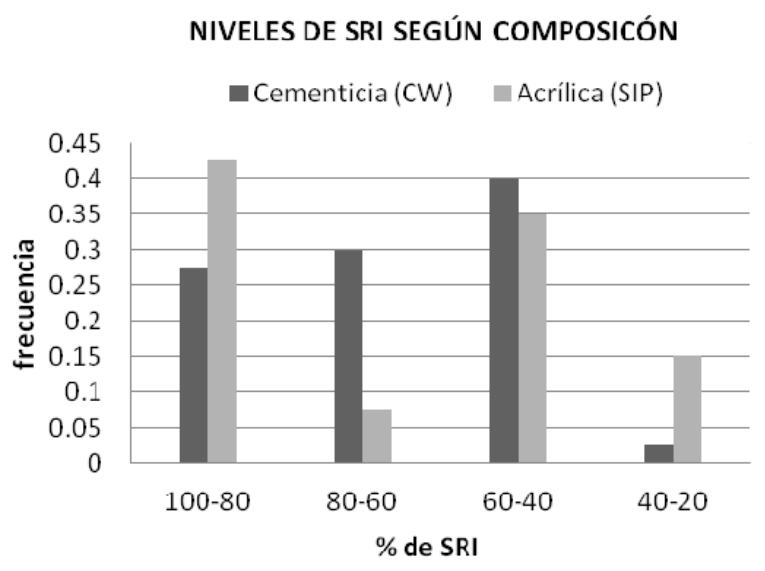

Figura 7 - Índice de Reflectividad Solar, según Composición del Revestimiento

\section{Diferencias térmicas entre Composición acrílica y cementicia en la textura Granitex Medio}

Si dejamos constante la textura y la terminación y evaluamos la incidencia de la composición, vemos para el caso de la textura Granitex medio en ambas composiciones que el revestimiento SIP (acrílico) muestra mejor desempeño térmico que el $\mathrm{CW}$ (cementicio) en las tonalidades claras (blanco, marfil y ocre). Por ejemplo: el revestimiento acrílico Granitex medio ocre - SIP 36 -, eleva $12^{\circ} \mathrm{C}$ menos que el cementicio Granitex medio ocre CW 76.

En los colores piedra parís, terracota, gris perla, verde hormigón y gris plomo, que son tonalidades de albedos inferiores en general ( $\hat{a}=0.32$ a 0.73 ), esta tendencia se invierte. Es decir, que los materiales cementicios de pigmentaciones oscuras, poseen mayores niveles de SRI que los acrílicos de igual tonalidad. Tal es el caso del revestimiento cementicio Granitex medio gris plomo - CW 80 -, presenta un SRI 44\% inferior a la del acrílico Granitex medio gris plomo - SIP 40 (Tabla 3, Figura 8). 


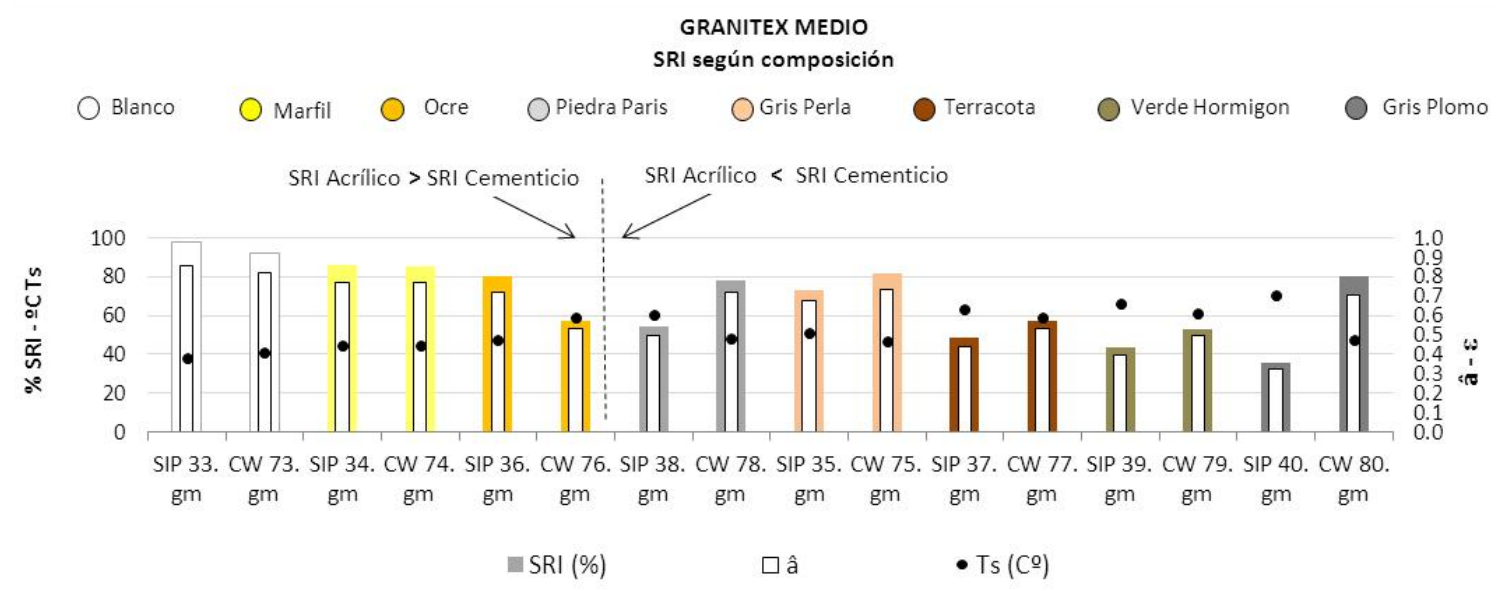

Figura 8 - Comportamiento de la textura Granitex medio, según color para cada composición

\section{Segunda etapa de análisis}

\section{Revestimientos Acrílicos (SIP)}

\section{Casos extremos dentro de los revestimientos acrílicos (SIP)}

Los materiales acrílicos que poseen mayor habilidad para disminuir las cargas de calentamiento dentro de la ciudad presenta alta reflectividad y emisividad (selectivo frío): son el Rulato travertino fino marfil - SIP02 - con una T $35^{\circ} \mathrm{C}$ y un SRI de $100 \%$ y el Llaneado fino piedra parís - SIP19 -; en segundo lugar se ubica el Rulato grueso marfil - SIP10.

Los revestimientos más desfavorables son en orden ascendente: el Llaneado fino gris plomo SIP24 - con una $\mathrm{Ts}=74^{\circ} \mathrm{C}$ y un SRI de $29 \%$, en segundo lugar el Llaneado grueso gris plomo SIP32 - y por último el Granitex medio - SIP40. En los tres materiales los niveles de SRI no superan el $40 \%$.

Sintetizando, los casos extremos analizados presentan diferencias superiores al $70 \%$ en su capacidad para mitigar los efectos de la Isla de Calor. Ver revestimiento - SIP02 - vs. - SIP24 cuya diferencia térmica es de $39^{\circ} \mathrm{C}$. (Tabla 3 , Figura 10).

\section{Registros térmicos entre diferentes colores a igual textura y terminación para revestimientos acrílicos (SIP)}

El color más eficiente para la textura Rulato travertino de terminación fina (rf) y gruesa (rg) es el marfil. El revestimiento Rulato travertino fino marfil - SIP $02-$ posee una $\mathrm{Ts}=35^{\circ} \mathrm{C}$ y el Rulato travertino grueso marfil $-\mathrm{SIP} 10-$ tiene una $\mathrm{Ts}=38$ ${ }^{\circ} \mathrm{C}$.

En la textura Llaneada de terminación fina (lf) el color más frío es piedra paris, mientras que en el acabado grueso (lg) es el blanco. El Llaneado fino piedra paris - SIP19 - alcanza una $\mathrm{Ts}=35^{\circ} \mathrm{C}$ y el Llaneado grueso blanco - SIP25 - es de $40{ }^{\circ} \mathrm{C}$.

Para la textura Granitex medio el color con menor temperatura es el blanco - SIP33 - con una $\mathrm{Ts}=39^{\circ} \mathrm{C}$ (Tabla 3, Figura 9).

En la Figura 9 se presentan discriminados por textura y terminación el SRI de cada uno de los colores que integran las muestras.

Del total de los colores estudiados en los revestimientos acrílicos el blanco es la tonalidad que registra un comportamiento más eficiente. Alcanza el mayor nivel de reflectividad solar promedio, $\mathrm{SRI}=93 \%$. En segundo lugar se ubica el color marfil con un $\mathrm{SRI}=81 \%$.

Se debe prestar especial atención al color marfil en su condición de textura Llaneada fina (lf). Dado que el revestimiento Llaneado fino marfil - SIP18 - posee menor reflectividad solar $(\mathrm{SRI}=55 \%)$ en comparación a las muestras de igual textura y terminación en color piedra parís - SIP19 -, ocre SIP20 -, y gris perla - SIP20. Para éstos casos, las diferencias de SRI alcanzan porcentajes de $45 \%$, $40 \%$ y $32 \%$ respectivamente (Evaluar la condición del color marfil para la textura llaneado fino respecto de su comportamiento en las texturas restantes que se observa en la Figura 11). 


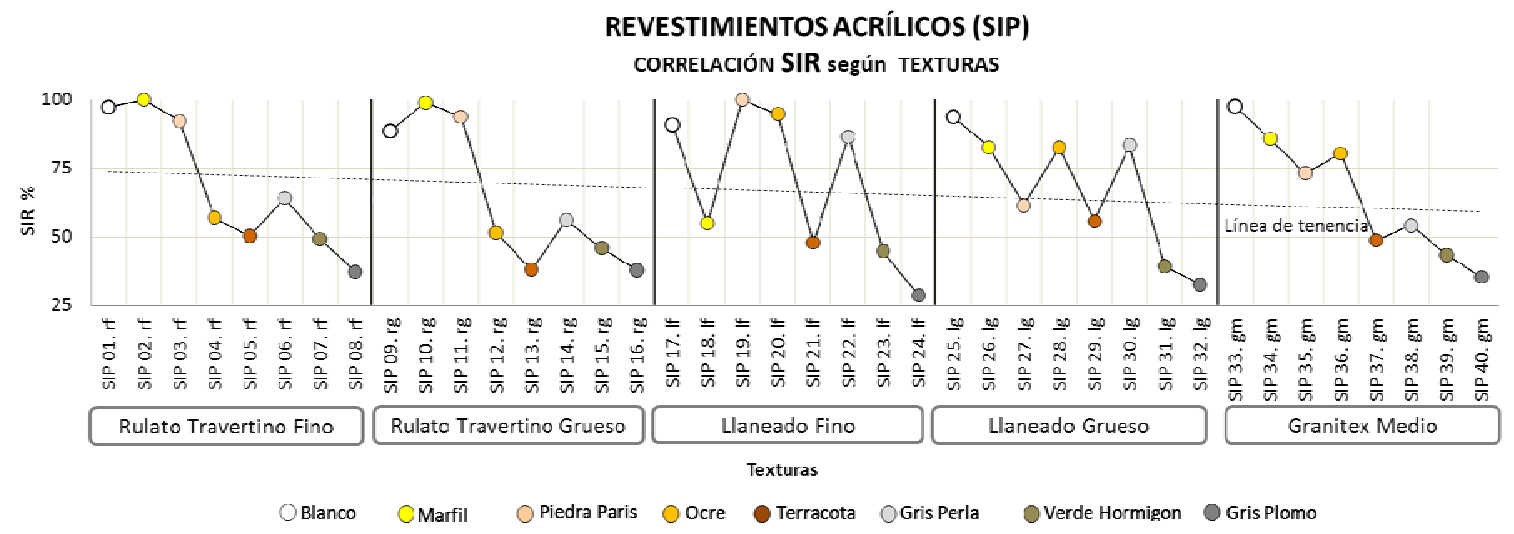

Figura 9 - Índice de Reflectancia Solar de Revestimientos Acrílicos según clasificación de textura para cada color

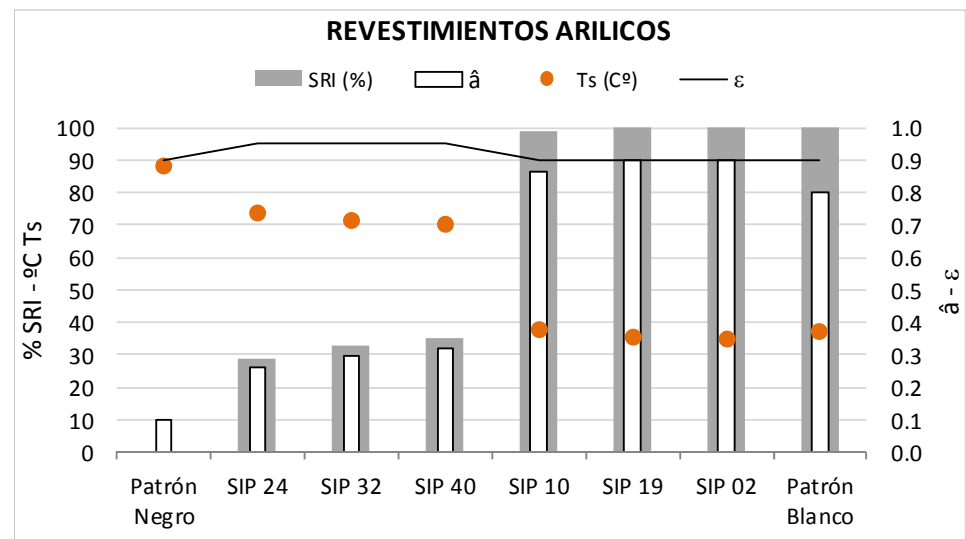

Figura 10 - Índice de Reflectividad Solar de Revestimientos Verticales Acrílicos

Nota: se graficaron solo los tres materiales que poseen mayor y menor habilidad para disminuir la ICU.

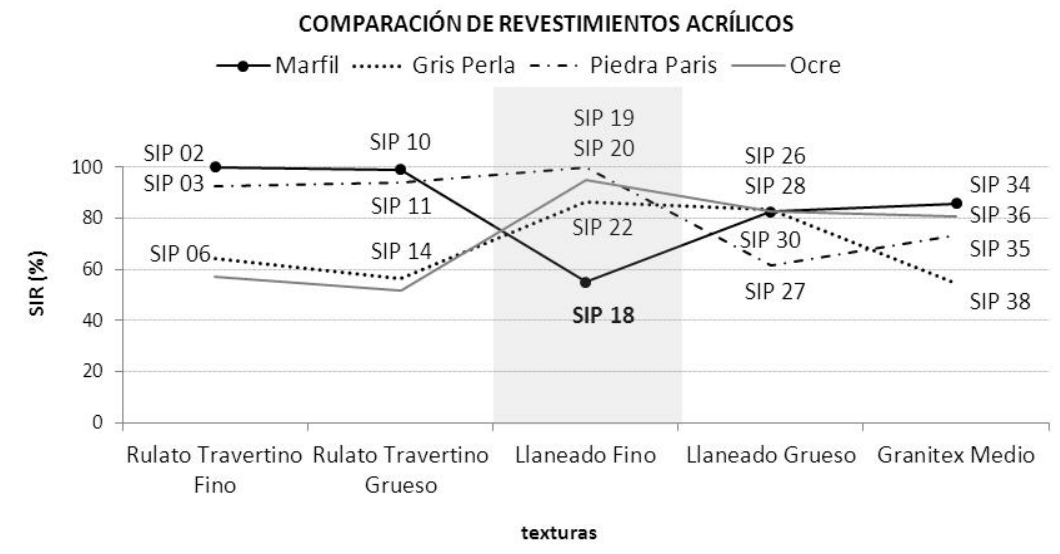

Figura 11 -Revestimientos Llaneado fino marfil, gris perla y piedra parís y su habilidad para disminuir las cargas de enfriamiento 


\section{Registros térmicos entre diferentes texturas a igual color para revestimientos acrílicos (SIP)}

La textura que presenta mayor SRI para las muestras de color blanco es la Granitex medio. El revestimiento Granitex medio blanco - SIP33 alcanza una $\mathrm{Ts}=39^{\circ} \mathrm{C}$ y un índice SRI de $98 \%$.

En los colores marfil, verde hormigón y gris plomo, la textura más eficiente es el Rulato travertino fino. El revestimiento Rulato travertino fino marfil $-\mathrm{SIP} 02$ - tiene una $\mathrm{Ts}=35^{\circ} \mathrm{C}$; el verde hormigón - SIP07 - alcanza $\operatorname{los} 63^{\circ} \mathrm{C}$ de temperatura superficial y por último el color gris plomo - SIP08 - una Ts $=69^{\circ} \mathrm{C}$. SRI de $100 \%, 49 \%$ y $37 \%$ respectivamente.

Para los colores piedra parís, ocre y gris perla la textura más fría es el Llaneado fino. El revestimiento Llaneado fino piedra parís - SIP19 tiene una $\mathrm{Ts}=35^{\circ} \mathrm{C}$, mientras que el ocre - SIP20 alcanza $40^{\circ} \mathrm{C}$ y el gris perla $-\mathrm{SIP} 22-44^{\circ} \mathrm{C}$, con valores de SRI iguales a $100 \%, 95 \%$ e $87 \%$ respectivamente.

En el color terracota la textura que consigue un mejor comportamiento es el Llaneado grueso. El Llaneado grueso terracota - SIP29 - registra una $\mathrm{Ts}=60^{\circ} \mathrm{C}$ y un $\mathrm{SRI}=56 \%$ (Tabla 3, Figura 12).

En la Figura 10 se presentan discriminados por color el SRI de cada uno de las texturas y terminaciones que integran las muestras.

Es decir, de las cinco texturas acrílicas estudiadas, el revestimiento Llaneado fino (lf), es el acabado acrílico que alcanza mayores niveles de SRI promedio para todos los colores. (SRI promedio $=69 \%$ ).

\section{Registros térmicos entre diferentes terminaciones a igual textura para revestimientos acrílicos (SIP)}

Al comparar la influencia de la terminación en el comportamiento de las texturas Rulato travertino y Llaneado, se observa un comportamiento más favorable para la terminación fina que para la gruesa. Es decir que el Rulato travertino de acabado fino consigue un promedio de SRI 5\% superior a la terminación gruesa. Lo mismo sucede en los revestimientos de textura Llaneada, la terminación fina registra un SRI promedio $3 \%$ mayor que la opción gruesa.

\section{Revestimientos Cementicios (CW)}

\section{Casos extremos dentro de los revestimientos cementicios(CW)}

En el caso de los materiales de composición cementicia, el revestimiento más fresco es el Texturable rulato blanco - CW41 - con un registro de $\mathrm{Ts}=38^{\circ} \mathrm{Cy}$ SRI de $98 \%$. El Salpicrate planchado blanco - CW65 - se ubica en segundo lugar, con $94 \%$ de SRI. El albedo en ambos revestimientos es similar (entre 0.85 y 0.84 respectivamente), en cambio la emisividad en el primer caso resulta mayor $(\varepsilon=0.90)$ que en el segundo $(\varepsilon=0.80)$.

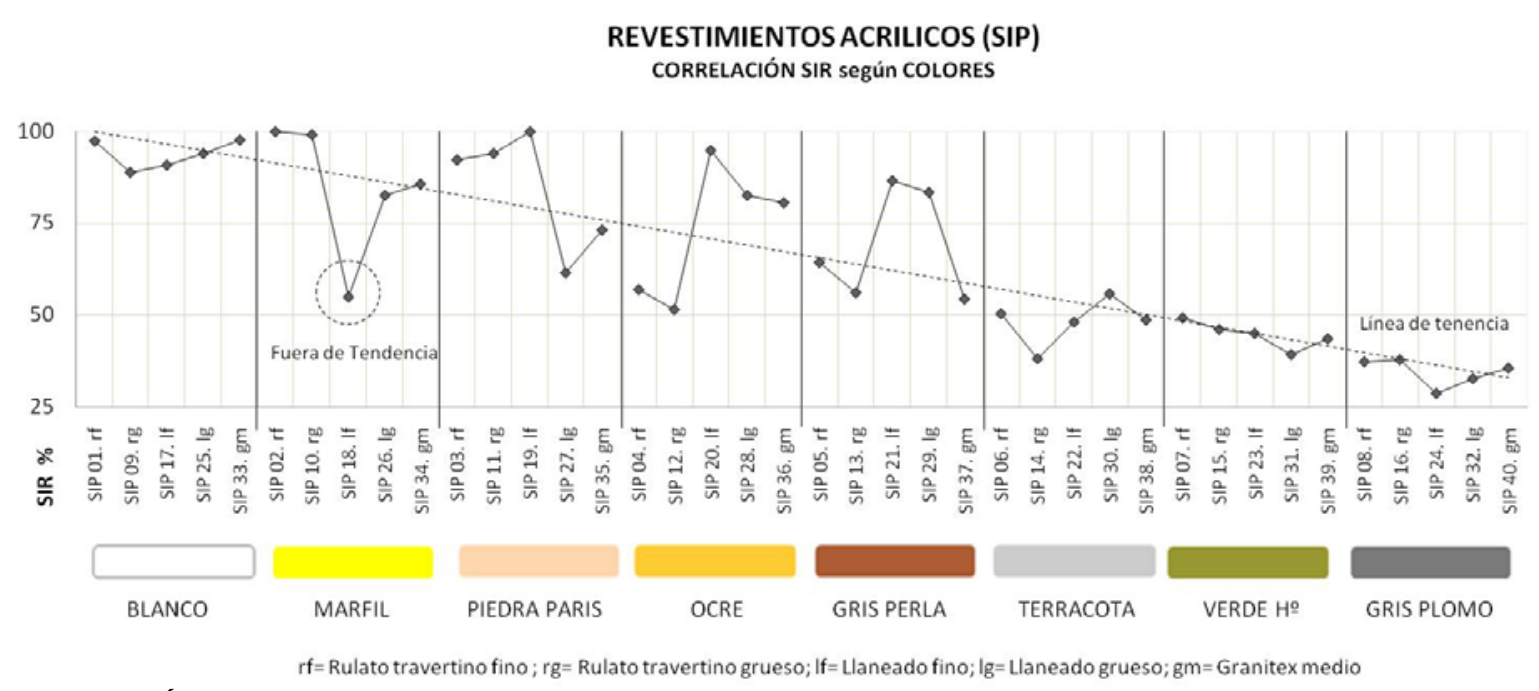

Figura 12 - İndice de Reflectancia Solar de Revestimientos Acrílicos según clasificación de color para cada textura 
Los materiales cementicios de peor funcionamiento respecto de las cargas térmicas de la ciudad son: el Texturable travertino - CW48, el Salpicrate salpic gris plomo - CW64 y por último el Salpicrate planchado gris plomo - CW72 - con temperaturas superficiales que oscilan entre los 67 y $68^{\circ} \mathrm{C}$ y SRI entre $41 \%$ y $40 \%$.

En adición entre los casos extremos, la temperatura superficial del revestimiento vertical cementicio Texturable rulato blanco - $\mathrm{CW} 41-$ es $30^{\circ} \mathrm{C}$ más frío que el Salpicrate planchado gris plomo CW72 -; con una diferencia de SRI del 58\% (Tabla 3, Figura 13).

\section{Registros térmicos entre diferentes colores a igual textura y terminación para revestimientos cementicios (CW)}

El color más frio en los revestimientos cementicios Texturable rulato (tr), Salpicrate planchado (sp) y
Granitex medio (gm) es el color blanco. El Texturable rulato blanco - CW41 - registra una $\mathrm{Ts}=38^{\circ} \mathrm{C}$, el revestimiento Salpicrate planchado blanco - CW65 - posee $40^{\circ} \mathrm{Cy}$ el Granitex medio blanco $-\mathrm{CW} 73-41^{\circ} \mathrm{C}$. Con valores de SRI entre $92 \%$ y $98 \%$.

Para la textura Texturable travertino (tt) el color que resulta más eficiente es el marfil. El Texturable travertino marfil - CW50 - alcanza una $\mathrm{Ts}=45^{\circ} \mathrm{C}, \mathrm{SRI}=86 \%$.

En la textura Salpicrate salpic (sp) se observan dos colores mayormente favorables: blanco y marfil. El Salpicrate salpic blanco - CW57 - al igual que el marfil - CW58 - tienen una Ts de $42^{\circ} \mathrm{C}$ y un SRI de 91\% (Tabla 3, Figura 14).

En la Figura 14 se presentan discriminados por textura y terminación el SRI de cada uno de los colores que integran las muestras.

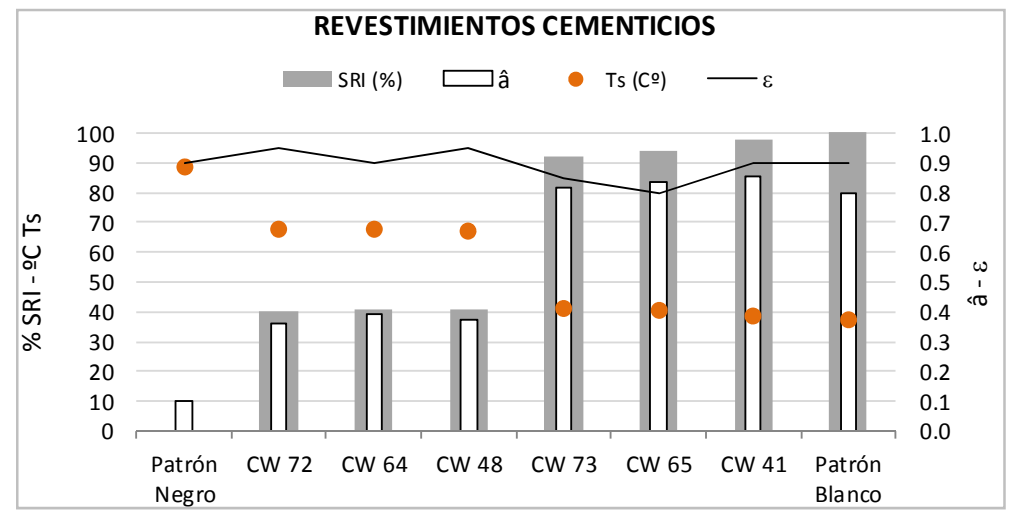

Figura 13 - Índice de Reflectividad Solar de Revestimientos Verticales Cementicios

Nota: se graficaron solo los tres materiales que poseen mayor y menor habilidad para disminuir la ICU.

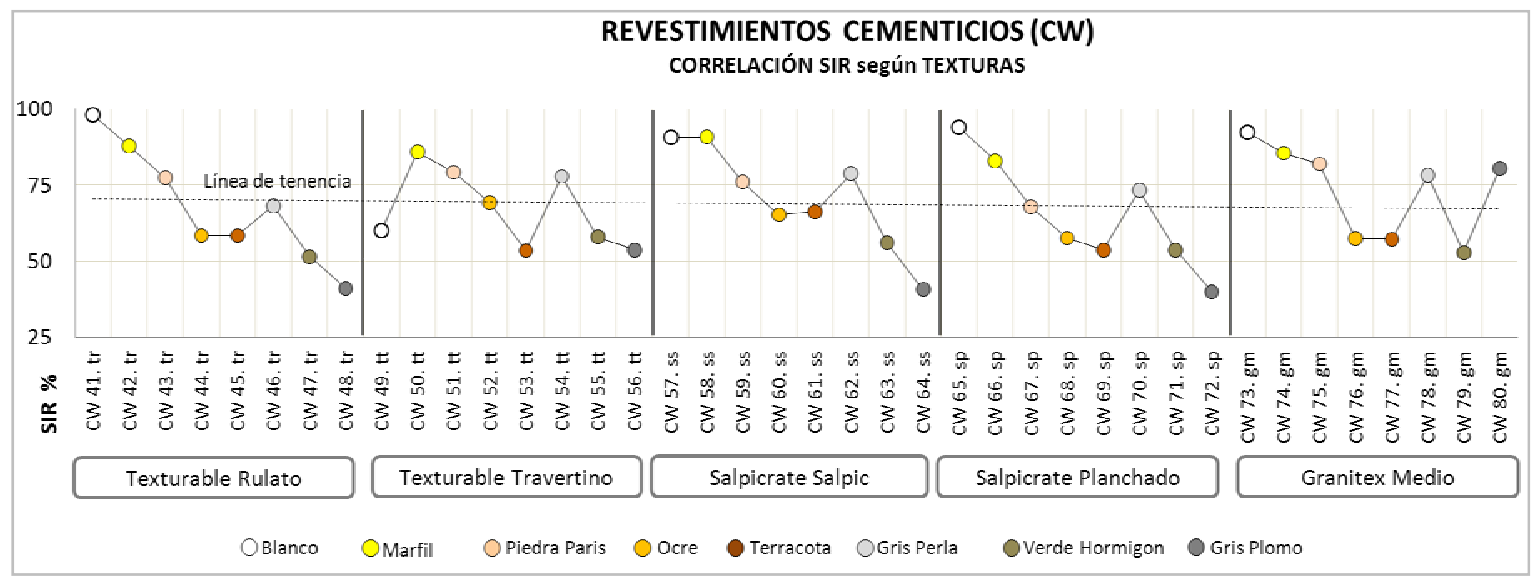

Figura 14 - Índice de Reflectancia Solar de Revestimientos Cementicios según clasificación de textura para cada color 
En adición, el color blanco en los revestimientos cementicios es la tonalidad que eleva menos su temperatura, con niveles de SRI que oscilan entre $60 \%$ y los $98 \%$.

\section{Registros térmicos entre diferentes texturas a igual color para revestimientos cementicios (CW)}

La textura que posee mejor nivel de SRI para el color blanco es el Texturable rulato (tr). El revestimiento Texturable rulato blanco - SIP41 registra una $\mathrm{Ts}=38^{\circ} \mathrm{C}$ y un $\mathrm{SRI}=98 \%$.

Para las tonalidades marfil, gris perla y terracota la textura más fría es el Salpicrate salpic (ss). El revestimiento Salpicrate salpic marfil - CW58 tiene una temperatura superficial de $42^{\circ} \mathrm{C}$, el gris perla - CW62 - de $48^{\circ} \mathrm{C}$ y la alternativa terracota CW61 - registra $55^{\circ} \mathrm{C}$. SRI de $91 \%, 79 \%$ y $66 \%$ respectivamente.

En los colores piedra parís y gris plomo la textura más eficiente es el Granitex medio (gm). Tanto el Granitex medio piedra parís - CW75 -, como el gris plomo $-\mathrm{CW} 80-$ alcanzan una $\mathrm{Ts}=47^{\circ} \mathrm{C}$ y un $\mathrm{SRI}=82 \%$ y $81 \%$ respectivamente.

Para el caso de las tonalidades ocre y verde hormigón la alternativa que muestra un mejor comportamiento es el Texturable travertino (tt). El revestimiento Texturable travertino ocre - CW52 registra una $\mathrm{Ts}=53^{\circ} \mathrm{C}$, mientras que el Texturable travertino verde hormigón - CW55 - consigue una temperatura superficial de $59^{\circ} \mathrm{C}$. SRI $69 \%$ y $58 \%$ respectivamente

En la Figura 15 se presentan discriminados por color el SRI de cada uno de las texturas y terminaciones que integran las muestras.

Al comparar la performance en el comportamiento térmico de las cinco texturas cementicias, el Granitex medio (gm) es el material que posee mayor habilidad para mitigar los efectos negativos de la ICU, con un SRI promedio en todas las tonalidades de $73 \%$ (Tabla 3,Figura 15).

\section{Registros térmicos entre diferentes terminaciones a igual textura para revestimientos cementicios (CW)}

Contrastando la eficiencia en el comportamiento térmico del revestimiento cementicio Texturable en la terminación rulato y la terminación travertino, se observó que ambas terminaciones muestran temperaturas superficiales muy similares. Con promedios de SRI de $68 \%$ y $67 \%$ respectivamente. No se aprecia influencia de la terminación para esta textura en el caso de los revestimientos cementicios.

En la textura Salpicrate en terminación salpic y planchado, la terminación salpic registra un SRI promedio de $71 \%$, mientras que en la terminación planchada es de $65 \%$. Es decir las diferencias por terminación alcanzan el $6 \%$.

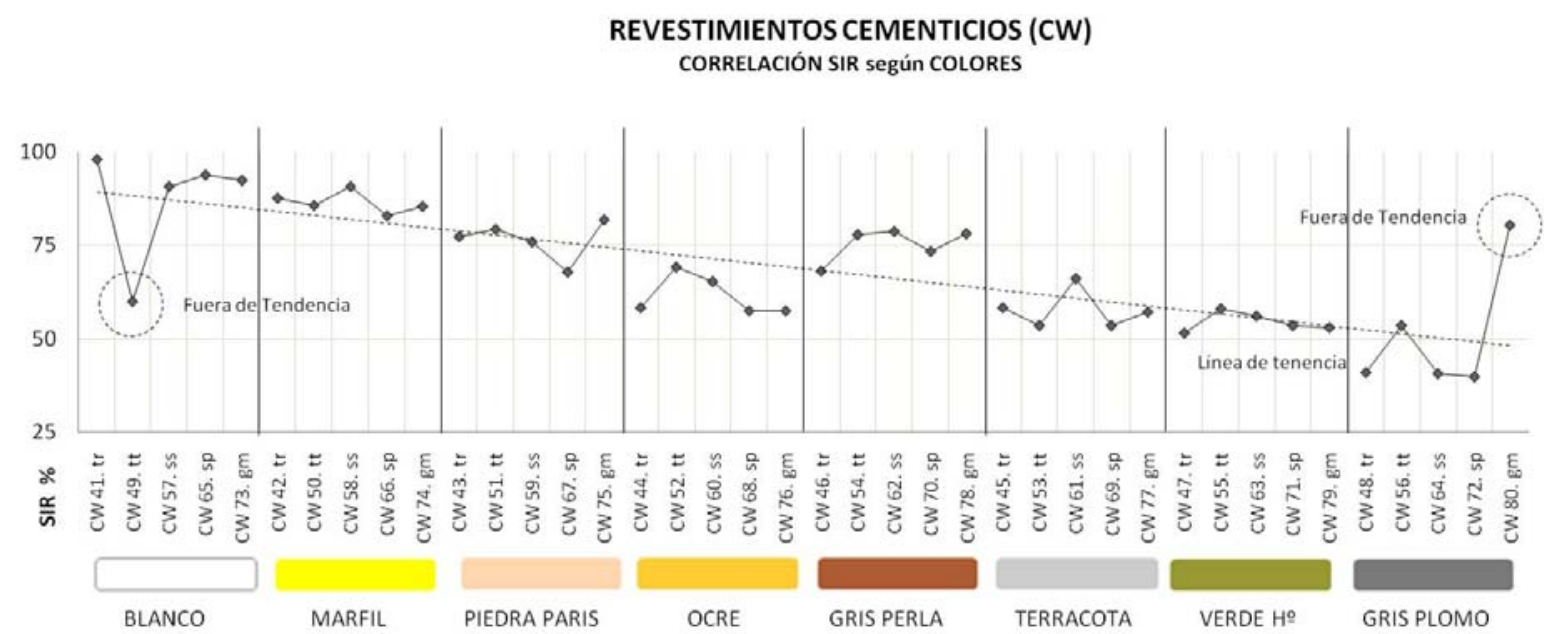

Figura 15 -Índice de Reflectancia Solar de Revestimientos Cementicios según clasificación de color para cada textura

Nota: Leyenda:

$\operatorname{tr}=$ texturable rulato;

$\mathrm{tt}=$ texturable travertino;

ss = salpicrate salpic;

$\mathrm{sp}=$ salpicrate planchado; $\mathrm{y}$

gm = granitex medio. 


\section{Conclusiones}

Los resultados obtenidos confirman la importancia de catalogar térmicamente los materiales disponibles regionalmente para la resolución de las envolventes a modo de transferir esta información a los responsables del desarrollo del hábitat en nuestra región. Los materiales que componen los espacios urbanos absorben la radiación solar e infrarroja y disipan hacia la atmósfera parte del calor acumulado. Es decir que el rol de la envolvente urbana desempeña un papel decisivo en la reducción de las ganancias térmicas y el sobrecalentamiento de una ciudad.

Las prestaciones térmicas de los revestimientos verticales se deben asociar al comportamiento simultáneo de la textura, color y composición. El aporte de este trabajo se sustenta en la valoración del SRI para cada uno de los materiales seleccionados. Las gráficas que derivan de este análisis, para cada tipo de composición, funcionan como un ábaco de fácil entendimiento y aplicación; y pueden ser utilizadas por los responsables del desarrollo del hábitat en el momento de seleccionar el revestimiento más adecuado que al mismo tiempo satisfaga sus necesidades estéticas y sea eficiente para disminuir las temperaturas urbanas.

Del análisis de las variables se observa que:

El color parece ser la variable de mayor impacto en la temperatura superficial de los revestimientos y en consecuencia sobre su Índice de Reflectancia Solar. Para los revestimientos acrílicos la tonalidad gris plomo versus la blanca, registra diferencias de temperatura que superan $\operatorname{los} 26^{\circ} \mathrm{C}$ y alcanzan diferencias en su índice de reflectividad solar superiores al $70 \%$. Se debe prestar especial atención al caso del material acrílico Llaneado fino, ya que el color marfil resulta ser muy desfavorable. Para éstas texturas llaneadas, la elección de los colores piedra parís y gris perla resulta ser la más adecuada.

Para el caso de los revestimientos cementicios en color blanco, el Texturable de terminación travertino posee $60 \%$ menos de índice de reflectividad solar que las restantes texturas de idéntico color. Es por ello que a pesar de ser un color claro no es aconsejable paraaplicar en las fachadas de la ciudad. Dentro de los colores oscuros, el material gris plomo Granitex medio, presenta gran eficiencia para disminuir las cargas térmicas, en comparación a las otras texturas.

La variable textura, evidencia que para los revestimientos acrílicos el Llaneado de terminación fino es el material con mayor habilidad para disminuir las cargas de calentamiento, alcanzando un promedio de SRI de $68 \%$.

En cambio, en las texturas de los revestimientos cementicios la mayor eficiencia es alcanzada por el Granitex de terminación medio ya que posee un valor de SRI superior al $73 \%$ promedio para los ocho colores estudiados.

De modo particular, en los revestimientos acrílicos la influencia de la terminación impacta de forma visible sobre el funcionamiento térmico del revestimiento, siendo la terminación fina claramente más beneficiosa que la gruesa (diferencia en la granulometría del acabado). Sin embargo, para los revestimientos cementicios esta influencia no es tan evidente. Una explicación posible es que para los revestimientos cementicios la terminación tiene que ver con el dibujo y no con su granulometría.

Respecto a la composición, el revestimiento acrílico de textura Granitex medio posee mejor SRI que los revestimientos cementicios en las tonalidades claras (blanco, marfil y terracota). El hecho inverso se observa en las tonalidades oscuras (gris perla y plomo, piedra parís, terracota $\mathrm{y}$ verde) dónde la composición cementicia resulta más eficiente respecto a la acrílica.

En futuras etapas, se estudiará el comportamiento térmico de los materiales en el periodo invernal y $\mathrm{su}$ respuesta al envejecimiento para ambas estaciones. Con ello se pretende obtener una visión global del comportamiento de los materiales, debido a que la temática abarca tanto los requerimientos térmicos de verano como de invierno, y la realidad demuestra que los pigmentos cambian su apariencia con el paso del tiempo.

Finalmente determinar el impacto de la implementación de las distintas alternativas sobre los consumos energéticos anuales de estructuras urbanas y edilicias, es el desafío a afrontar en próximas investigaciones. Así como también correlacionar factibilidades de uso y costo.

\section{Referencias}

AMERICAN SOCIETY FOR TESTING AND MATERIALS. ASTM E-1933-99a: standard test methods for measuring and compensating for emissivity using infrared imaging radiometers. 2006.

AMERICAN SOCIETY FOR TESTING AND MATERIALS. ASTM E-1980: standard practice for calculating solar reflectance index of horizontal and low-sloped opaque Surfaces. 2011a. 
AMERICAN SOCIETY FOR TESTING AND

MATERIALS. ASTM D2244:standard practice for calculation of color tolerances and color differences from instrumentally measured color coordinates. $2011 \mathrm{~b}$.

BRETZ, S.; AKBARI, H. Long-Term Performance of High Albedo Roof Coatings. Energy and Buildings, v.25, n. 2, p.159-167, 1997.

\section{COMISIÓN INTERNACIONAL DE LA ILUMINACIÓN. CIE. 1937.}

CORREA, E.; DE ROSA, C.; LESINO, G. Acondicionamiento Térmico de los Espacios: estudio del Potencial de Enfriamiento Evaporativo Adiabático dentro del Area Metropolitana de Mendoza, Argentina. AVERMA. Avance en Energías Renovables y MedioAmbiente, v. 11, n. 1, p. 113-120, 2007.

DOULOS, L.; SANTAMOURIS, M.; LIVADA, I. Passive Cooling of Outdoor Urban Spaces: the Role of Materials. Solar Energy, v. 77, n. 2, p. 231-249, 2004.

DUFFIE, J. A.; BECKMAN, W.A. Solar Engineering and Thermal Processes. New York: John Wiley \& Sons, 1991.

INSTITUTO NACIONAL DE ESTADÍSTICA Y CENSOS. Censo Nacional de Población, Hogares y Viviendas. 2010. Disponibel en: $<$ http://www.indec.mecon.ar/>. Acceso: 23 ago. 2012.

KIPP \& ZONEN. Product Catalogue. Disponible en: <http://www.kippzonen.com/>. Acceso: 1 mar. 2012.
MINISTERIO DE PLANIFICACIÓN FEDERAL, INVERSIÓN PÚBLICA Y SERVICIOS.

Secretaría de Energía. Instituto Nacional de

Estadísticas y Censos. Disponible en:

$<$ http://www.indec.mecon.ar/>. Acceso: 23 ago. 2012.

OKE, T.et al. Simulation of Surface Urban Heat Island Under 'Ideal' Conditions at Night: part 2: diagnosis and causation. Boundary-

LayerMeteorology, v. 56, p. 339-358, 1991.

SANTAMOURIS, M.; PARAPONIARIS, K.; MIHALAKAKOU, G. Estimating the Ecological Footprints of the Heat Island Effect, Athens, Greece. Climate Change, v.80, p.265-276, 2007.

SANTAMOURIS, M; SYNNEFA, A;

KARLESSIET, T. Using Advanced Cool Materials in the Urban Built Environment to Mitigate Heat Islands and Improve Thermal Comfort Conditions. Solar Energy, v. 85, n. 12, p. 3085-3102, 2011.

SANTAMOURIS, M.et al.Recent Progress on Passive Cooling Techniques: advanced technological developments to improve survivability levels in low-income households. Energy and Buildings, v. 39, n. 7, p. 859-866, 2007.

SIEGEL, R.; HOWELL, J. Thermal Radiation Heat Transfer. $4^{\mathrm{TH}}$.New York: Taylor and Francis, 2002.

STATHOPOULOU, E.et al. Impact of Temperature Ontropospheric Ozone Concentration Levels in Urban Environments.Journal of Earth System Science, v. 117, n. 3, p. 227-236, 2008.

Revista Ambiente Construído

Associação Nacional de Tecnologia do Ambiente Construído

Av. Osvaldo Aranha, 99 - 3o andar, Centro

Porto Alegre - RS - Brasil

CEP 90035-190

Telefone: +55 (51) 3308-4084

Fax: +55 (51) 3308-4054

www. seer. ufrgs. br/ ambienteconstruido

E-mail: ambienteconstruido@ufrgs.br 